\title{
The use of a dual mobility cup in the management of recurrent dislocations of hip hemiarthroplasty
}

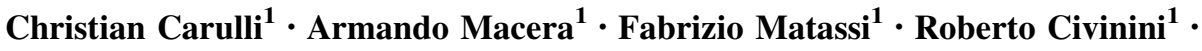 \\ Massimo Innocenti ${ }^{1}$
}

Received: 29 December 2014/ Accepted: 15 June 2015/Published online: 18 July 2015

(C) The Author(s) 2015. This article is published with open access at Springerlink.com

\begin{abstract}
Background Dislocation is one of the most frequent causes of failure of hemiarthroplasties of the hip, which is the most common treatment for femoral neck fractures in elderly patients. A revision with conversion to total hip arthroplasty is the gold standard in case of failure of closed reduction: however, the use of standard or modular components shows variable outcomes. The use of a dual mobility cup has been evaluated in patients with unstable implants, given the good outcomes obtained in primary and revision surgery. The aim of this study was to assess the results of revisions by dual mobility cups in unstable hemiarthroplasties.

Materials and methods Thirty-one patients (mean age 75.4 years) were retrospectively evaluated between 2006 and 2010 after conversion to total hip arthroplasty with dual mobility cups for recurrent dislocations. The mean number of dislocations was 2.6 (range 2-5). The evaluation was performed by the American Society of Anesthesiologists physical function score (ASA) and the Harris hip score, and several radiologic criteria.

Results The mean follow-up was 3.8 years. No recurrence of dislocation was recorded. The ASA score remained unchanged, and the mean Harris hip score improved from 62.2 before dislocation to 76.0 points postoperatively.

Conclusions Dual mobility cups may be a useful option in the treatment of a hemiarthroplasty dislocation. No risk of a new revision due to instability after insertion of dual mobility cups resulted in our experience, and this option
\end{abstract}

Christian Carulli

christian.carulli@unifi.it

1 Orthopaedic Clinic, University of Florence, Largo P. Palagi 1, 50139 Florence, Italy may be strongly considered in cases of revisions of unstable hemiarthroplasties.

Level of evidence IV.

Keywords Dislocation - Hemiarthroplasty of the hip . Dual mobility cups $\cdot$ Revision

\section{Introduction}

Dislocation is one of the major causes of failure of a hemiarthroplasty of the hip (HAH). Its incidence is rated at 6-10\% with respect to $2-3 \%$ for total hip arthroplasty (THA) [1, 2]. Dislocations occur typically within 6 months after surgery [3], particularly in the first 2-6 weeks. Several factors have been advocated, such as sex, cognitive status, anatomy of the acetabulum (related to patients); femoral head diameter, femoral stem rotation and off-set, surgical approach and excessive removal of joint capsule (related to surgeons) $[4,5]$. It is crucial to understand the causes of dislocation before facing surgery with an adequate strategy, in order to limit the recurrence of the instability. Several procedures have been proposed depending on the cause of the dislocation: repositioning of femoral stem [6], conversion to THA [6, 7], revision with traditional or modular neck components [7-10], use of constrained components [11, 12], trochanteric advancement [13], removal of acetabular or femoral osteophytes [6], and repair of the abductor muscles and of the joint capsule $[14,15]$. However, all these procedures showed rates of success ranging from 60 to $80 \%$, independently by the cause leading to instability [6, 10, 13, 16-19]. Particularly, the conversion of HAH to THA demonstrated discouraging results with reports of even worse failure rates than a full revision [6,7]. The implant of constrained 
acetabular inserts also showed variable results, with a high risk of increased wear, osteolysis, and instability in THA $[11,12]$. Revisions of unstable THAs are generally considered technically demanding procedures [20-22]. Recently, good results have been obtained by the use of "dual mobility" cups for revisions of unstable THAs [2331] and primary implants after femoral neck fractures [32], in terms of limitation of dislocation recurrence and preservation of a wide range of motion (ROM): low wear is also expected. To date, no report addresses similar outcomes for the management of unstable HAHs treated by revisions with dual mobility cups.

The purpose of this study was to assess the short-term results of a series of patients affected by unstable HAHs managed by a conversion to THA with dual mobility cups.

\section{Materials and methods}

We retrospectively reviewed 31 patients (31 hips) affected by recurrent dislocations of $\mathrm{HAH}$, treated by a conversion to THA with dual mobility cups between 2006 and 2010. All patients had been given bipolar cemented implants for femoral neck fractures: the index operation was performed with a mean interval of 2.4 days (range 1-3) after patient admission to the emergency room. Eighteen patients were female and 13 male, with a mean age of 75.4 years (range 71-86) at the time of fracture. The right side was affected in 17 cases; the left side in 14 cases. Eleven patients were operated on in other hospitals, while 20 were operated on at the authors' institution. All patients were operated on by a lateral approach at the time of HAH. The mean interval to the first dislocation after HAH was 23.2 days (range 1-46). The mean number of dislocations was 2.6 (range 2-5). Dislocations were mostly posterior (29 cases); one subject showed a dislocation in an anterior direction; only one case was multidirectional (a single patient with five episodes of instability).An evaluation of the associated risk factors of patients was made before proceeding to revision. The mean time between the HAH and the revision in arthroplasty was 3.2 years (range 7 months-6 years). The American Society of Anesthesiologists physical function (ASA) score based on the severity of patients' comorbidities was evaluated [33]. The ASA score at the time of revision was III in 19 patients, IV in six subjects, and II in the remainder. Several pathologies were present, and a high risk of dislocation was considered in some patients: three cases of Parkinson's disease, three cases of diabetes mellitus with severe peripheral neuropathy, one case of critical peripheral arterial disease, two severe cognitive impairments related to Alzheimer's disease, one hemiparesis as the result of a previous stroke, and one of severe pluriarticular rheumatoid arthritis. The Harris hip score (HHS) was also recorded [34]. A radiographic study by anteroposterior and lateral views was conducted to study the femoral stem position according to Loudon and Charnley [35], and the stability of the components as described by Engh et al. [36]. The presence of radiolucent lines and osteolysis of periprosthetic bone were assessed by the criteria of DeLee and Charnley, and Gruen et al. [37, 38]. Cup inclination was assessed in the anteriorposterior projection, measuring in degrees the angle formed by a line drawn along the bottom of the acetabular component intersecting with the horizontal inter-teardrop line. Hip centre restoration was assessed by calculating the perpendicular distance from the prosthetic centre of rotation to a horizontal line drawn between the tips of the teardrops. Limb length was evaluated. Finally, the presence of periarticular ossification was also evaluated by Brooker's classification [39]. Collaborative patients, or relatives of poorly oriented subjects were adequately informed, and approved the treatment and follow-up. Surgery was performed by two surgeons, in all cases by a direct lateral approach through the previous surgical scars. In 19 cases a general anaesthesia was performed (ASA score: IV in six patients, III in 13); in 12 cases, a locoregional anaesthesia was chosen. In 25 cases, a capsular laxity was present, while in the remaining patients the capsule was mostly absent. When possible, capsulae were sutured and soft tissues reconstructed after the cup positioning. In all cases a dual mobility acetabular cup was implanted as porous coated press-fit or cemented (Avantage ${ }^{\circledR}$, Biomet, Warsaw, IN, USA). This component consisted of a metal cup with a polished inner surface articulating with a high molecular weight polyethylene bipolar insert (acting as a large diameter head) containing a 28-mm chrome-cobalt head. In 20 cases, a press-fit cup was implanted (Fig. 1): three cups needed a further fixation by two or three acetabular screws. In the remainder, a cemented cup was implanted (Fig. 2). Criteria leading to the use of a cemented cup were poor bone quality or a significant enlargement of the native diameter of the acetabulum as tested intraoperatively during acetabular preparation. Cups sizes between 44 and $56 \mathrm{~mm}$ were used. Actually, in a single case we also proceeded to the revision of the cemented femoral stem, given the remarkable rotational malposition of the component and the length discrepancy $(2 \mathrm{~cm})$ : a new larger cemented femoral stem was used (MS-30 ${ }^{\circledR}$, Biomet, Warsaw, IN, USA). In 12 patients, a long (eight cases) or extra-long (four cases) 28-mm head was implanted to ensure an adequate offset and further stability. The prophylaxis of heterotopic ossifications was made by Indometacin $25 \mathrm{mg}$ t.i.d. for 3 weeks in patients without any contraindications related to other comorbidities or concomitant therapies. Parameters such as blood loss, following the criteria of Liu et al. [40], surgical time, and early postoperative complications were recorded. Postoperative care consisted of a short period of immobilization 

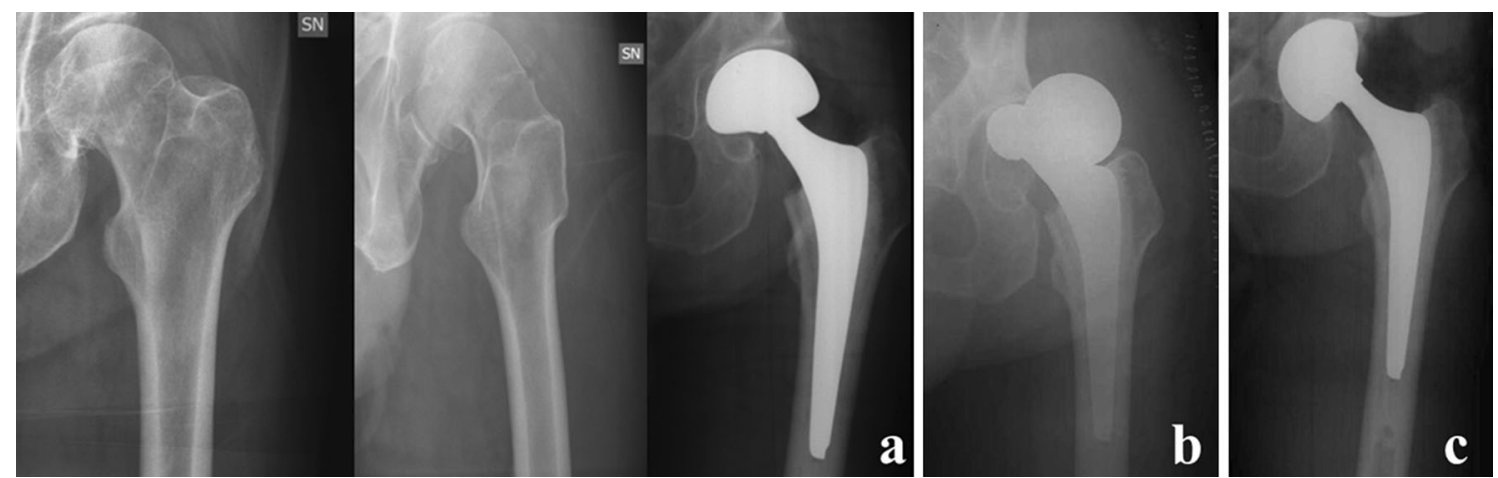

Fig. 1 A left femoral fracture of a 72-year-old male patient, treated by a hemiarthroplasty of the hip (a); 3 weeks postoperatively, a dislocation of the implant occurred (b), and conversion to total hip replacement by a pressfit dual mobility cup was performed (c)
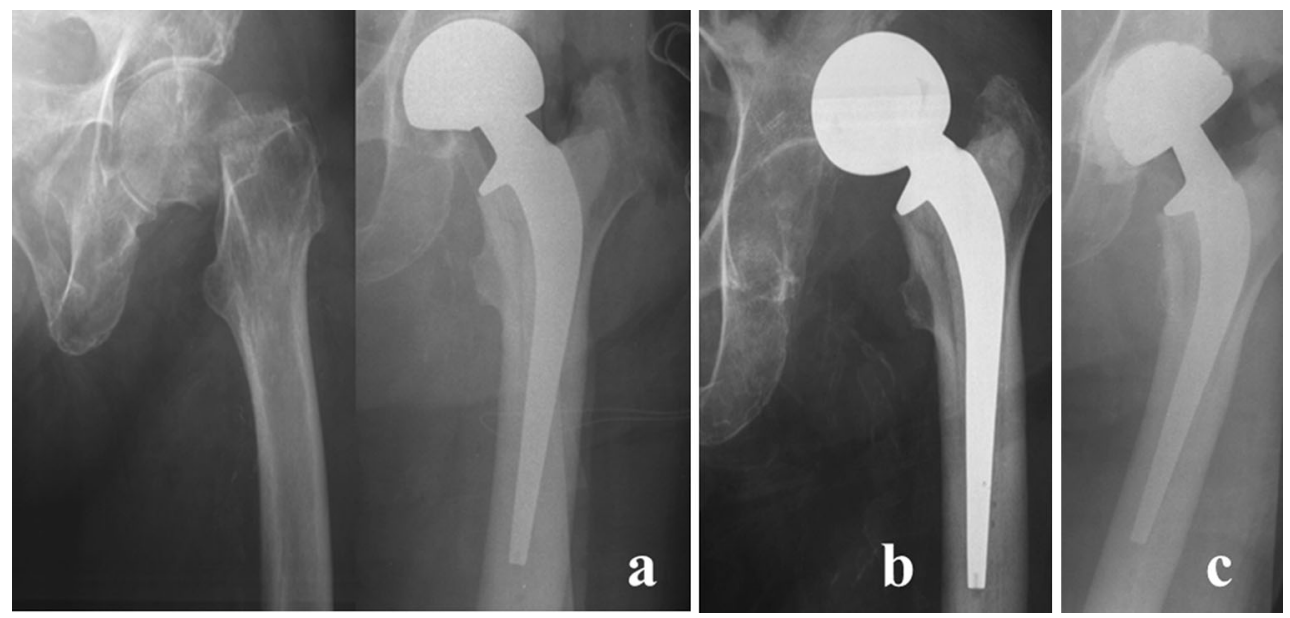

Fig. 2 A left femoral fracture of a 79-year-old female patient, affected by Alzheimer's disease, and treated by a hemiarthroplasty of the hip (a); 4 days after surgery, a dislocation occurred, treated by

with a pillow between the legs in order to limit adduction of the hips. An assisted passive motion protocol from the 3rd postoperative day was then performed. Active exercises, partial weight-bearing, and assisted gait activities were then specifically prescribed for each case, depending on pain and patients' collaboration. All patients were clinically and radiographically evaluated at 1 month after surgery, and after 3, 6, and 12 months. After this follow-up, all the subjects were encouraged to attend a yearly follow-up.

Considering the small size of the study population, only the Wilcoxon signed rank test was used to compare preand postoperative HHS scores.

\section{Results}

All patients were followed at least for 2 years, with a mean follow-up of 3.8 years (range 2-7 years). The average blood loss was $210 \mathrm{cc}$ (range 100-400), and the mean closed reduction under anaesthesia (b). A second dislocation recurred after 5 days, thus a cemented dual mobility cup was implanted (c)

surgical time was 57.8 min (range 45-120). Seven patients were assisted after surgery in an intensive care unit for 24-48 h. No intraoperative complication was recorded. Postoperative complications were present in six cases $(19.3 \%)$ : three deep vein thromboses (one unilateral, one bilateral) managed by a mechanical compression and therapeutic doses of low-molecular-weight heparin; one case of urinary tract infection, treated by antibiotics; one case of superficial wound infection, managed by an advanced wound care treatment and oral antibiotics; and one case of an acute imbalance in diabetes mellitus, managed by tailored insulin therapy.

No case of dislocation was recorded during the mentioned follow-up. Radiographic studies revealed radiolucent lines in zone 2 according to DeLee and Charnley in three patients (all with cementless cups). However, these were not progressive and were less than $2 \mathrm{~mm}$ in width: these cups were correctly implanted. In three additional cases radiolucent lines of about $1 \mathrm{~mm}$ without progression around the femoral component 
were found in zone 1 (the only patient with the stem revision) and zone 5 (two patients) according to Gruen et al. The mean cup inclination was $45.4^{\circ}$ (range $42-49^{\circ}$ ). An adequate hip centre restoration was achieved in 23 cases. A suboptimal hip centre was achieved in the remaining subjects; however, due to good stability, the patients accepted well the residual length discrepancy (in all cases $<1.5 \mathrm{~cm}$ ). No osteolysis, significant subsidence, or cement mantle fractures were noted, according to the criteria of Loudon and Charnley. No implant was found to be unstable or poorly stable according to Engh's classification. We recorded three cases $(9.6 \%)$ of heterotopic ossifications grade 1 and one grade 2 (the patient with the revised stem), without, however, referred symptoms or functional impairments: two of them did not undergo prophylaxis due to clinical contraindications.

The pillow was maintained for an average interval of 2.8 days (range 2-4). The mean HHS improved from 62.2 points (range 34-75) before the dislocation to 76.0 points (range 71-80) postoperatively with a significant difference $(p=0.002)$. The ASA score remained basically stable after surgery in all the patients. Symptoms and functional disability progressively decreased over the follow-up period, allowing all patients without neurologic impairments to return to their common daily activities. Poorly or uncollaborative patients were not substantially able to complete a full functional recovery, however, without further episodes of dislocation.

\section{Discussion}

Dislocations of HAHs are generally associated with an insufficient restoration of the centre of rotation or other mechanical problems due to a wrong primary implantation. The conversion of an unstable HAH to a standard THA is a procedure with a high risk of further dislocations, with an incidence often higher than revision THA itself [2, 20-22, 41, 42]. Several reasons have been advocated: the reduction of the diameter and offset of the femoral head, which may produce an inadequate soft tissues tension; the inappropriate positioning of a retained femoral stem, frequently maintained to avoid long surgical procedures in critical patients; and the insufficient retaining properties of the acetabular cup/liner complex. Several other options such as the use of a cemented cup with a structural bone graft fixed with screws, threaded cups with or without bone grafting, constrained cups, reinforcement rings, or "anti-protrusio" cages have been proposed over the decades. Variable results have been obtained in cases of acetabular discontinuity or severe bone loss, poor acetabular rim coverage, and substantial alterations of shape of the acetabulum [43, 44]. In the remaining cases, outcomes were not satisfactory.
Figved et al. [20] reported a lower risk of complications, including instability, based on the Norwegian Arthroplasty Register, in cases of conversion of HAH to THA with stem revisions, compared to stem retaining procedures. Moreover, in the same series, modular implants for revision presented more advantages related to head size, neck length, and worn head replacement. However, no mention of dual mobility cups has been described.

Only a few studies showed no relationships or even higher rates of dislocation between large diameter heads and the risk of instability in primary and revision implants [41, 42]. Llinas et al. [21] reported the long-term outcomes of a series of failed HAHs treated with THA with traditional components: higher rates of earlier radiologically detected loosening of acetabular components inserted following HAH failure were found with respect to primary THAs. No mention of dual mobility cups was made in this series.

Constrained cups and liners have been proposed over the years with variable results $[11,12]$. Reduction of ROM related to component impingement, increased wear related to high local stresses, and higher risk of loosening were considered the reasons related to significant rates of failure of these implants [23-25].

Dual mobility cups and large femoral heads have their rationale in limiting instability, ensuring a wide ROM with respect to traditional implants, and maintaining low wear in primary and revision hip arthroplasties. Satisfactory longterm outcomes have been reported in several series in primary and revision hip arthroplasty [23-31, 45]. A single multicentre study reported the use of this type of implant for the primary replacement in patients affected by a femoral fracture: a dislocation occurred in three cases out of 214 patients (1.4\%) within the first 3 months [46]. The authors found no recurrence of the dislocation in these patients treated by closed reduction under general anaesthesia, even if they used a posterior approach, generally associated with a higher risk of dislocation with respect to the direct lateral approach [47, 48]. However, to date there has been no significant experience regarding series of HAHs failed for instability and managed by revision with dual mobility cups. Bouchet et al. reported a statistically lower risk of dislocation for the dual mobility cup compared to a conventional $28-\mathrm{mm}$ head and polyethylene inserts implanted through a posterior approach. The instability rate was $0 \%$ compared with $4.63 \%$ for the conventional prostheses [25]. In our series, we recorded improvements in the HHS, and complication rates were comparable to other reports in the literature. Nonetheless, we had no recurrence of dislocation, and no specific failure related to choice of implants. A specific mechanism of failure of dual mobility cups is effectively represented by the intraprosthetic dislocation [49-51]. It consists of the 
loss of the polyethylene retentive rim, with escape of the femoral head from the liner that may manifest particularly in younger, high-demand patients undergoing a primary THA with this implant $[28,51]$. No similar complication was recorded in our series.

The present study has some limitations. It is a retrospective analysis with a small number of patients, and without a control group. However, we do not usually perform revisions with standard or constrained cups for unstable HAHs, using in most cases a dual mobility component: related costs are similar to other choices of treatments. Nevertheless, at short-term follow-up we had no recurrence of instability, with both versions (cemented and cementless) of the dual mobility cup.

We feel that dual mobility cups may be a useful and effective option worth considering in the treatment of HAH dislocations.

\section{Compliance with Ethical Standards}

Ethical standards The authors state that the study conforms to the 1964 Helsinki declaration and its later amendments; the study was approved by the local or institutional Ethical Review Board; all the patients provided informed consent before being enrolled.

Open Access This article is distributed under the terms of the Creative Commons Attribution 4.0 International License (http://crea tivecommons.org/licenses/by/4.0/), which permits unrestricted use, distribution, and reproduction in any medium, provided you give appropriate credit to the original author(s) and the source, provide a link to the Creative Commons license, and indicate if changes were made.

\section{References}

1. Iorio R, Healy WL, Lemos DW, Appleby D, Lucchesi CA, Saleh KJ (2001) Displaced femoral neck fractures in the elderly: outcomes and cost effectiveness. Clin Orthop Relat Res 383:229-242

2. Sah AP, Estok DM II (2008) Dislocation rate after conversion from hip hemiarthroplasty to total hip arthroplasty. J Bone Joint Surg Am 90:506-516

3. Blewitt N, Mortimore S (1992) Outcome of dislocation after hemiarthroplasty for fractured neck of the femur. Injury 23:320-322

4. Meek RMD, Allan DB, McPhillips G, Kerr L, Howie CR, From the Scottish Arthroplasty Project (2008) Late dislocation after total hip arthroplasty. Clin Med Res 6:17-23

5. Holmes JD, House AO (2000) Psychiatric illness predicts poor outcome after surgery for hip fracture: a prospective cohort study. Psycol Med 30:921-929

6. Daly PJ, Morrey BF (2002) Operative correction of an unstable total hip arthroplasty. J Bone Joint Surg Am 74:1334-1343

7. Berry DJ (2001) Unstable total hip arthroplasty: detailed overview. Instr Course Lect 50:265-274

8. Earll MD, Fehring TK, Griffin WL, Mason JB, McCoy T, Odum S (2002) Success rate of modular component exchange for the treatment of an unstable total hip arthroplasty. J Arthroplasty 17:864-869
9. McGann WA, Welch RB (2001) Treatment of the unstable total hip arthroplasty using modularity, soft tissue, and allograft reconstruction. J Arthroplast 16(Suppl. 1):19-23

10. Toomey SD, Hopper RH Jr, McAuley JP, Engh CA (2001) Modular component exchange for treatment of recurrent dislocation of a total hip replacement in selected patients. J Bone Joint Surg Am 83:1529-1533

11. Shapiro GS, Weiland DE, Markel DC, Padgett DE, Sculco TP, Pellicci PM (2003) The use of a constrained acetabular component for recurrent dislocation. J Arthroplast 18:250-258

12. Yun AG, Padgett D, Pellicci P, Dorr LD (2005) Constrained acetabular liners: mechanisms of failure. J Arthroplasty 20:536-541

13. Ekelund A (2003) Trochanteric osteotomy for recurrent dislocation of total hip arthroplasty. J Arthroplasty 8:629-632

14. Hughes AW, Clark D, Carlino W, Gosling O, Spencer RF (2015) Capsule repair may reduce dislocation following hip hemiarthroplasty through a direct lateral approach: a cadaver study. Bone Joint J 97-B:141-144

15. Weber M, Berry DJ (1997) Abductor avulsion after primary total hip arthroplasty: results of repair. J Arthroplast 12:202-206

16. Ali Khan MA, Brakenbury PH, Reynolds I (1981) Dislocation following total hip replacement. J Bone Joint Surg $\mathrm{Br}$ 63:214-218

17. Lind M, Krarup N, Petersen LG, Mikkelsen S, Horlyck E (2002) Acetabular revision for recurrent dislocations: results in 14 cases after 3 years of follow-up. Acta Orthop Scand 73:291-294

18. Morrey BF (2004) Results of reoperation for hip dislocation: the big picture. Clin Orthop Relat Res 429:94-101

19. Robbins GM, Masri BA, Garbuz DS, Greidanus N, Duncan CP (2001) Treatment of hip instability. Orthop Clin North Am 32:593-610

20. Figved W, Dybvik E, Frihagen F, Furnes O, Madsen JE, Havelin LI, Nordsletten L (2007) Conversion from failed hemiarthroplasty to total hip arthroplasty: a Norwegian Arthroplasty Register analysis of 595 hips with previous femoral neck fractures. Acta Orthopaedica 78:711-718

21. Llinas A, Sarmiento A, Ebramzadeh E, Gogan WJ, McKellop HA (1991) Total hip replacement after failed hemiarthroplasty or mould arthroplasty. Comparison of results with those of primary replacements. J Bone Joint Surg Br 73:902-907

22. Diwanji SR, Kim SK, Seon JK, Park SJ, Yoon TR (2008) Clinical results of conversion total hip arthroplasty after failed bipolar hemiarthroplasty. J Arthroplast 23:1009-1015

23. Guyen O, Chen QS, Bejui-Hugues J, Berry DJ, An KN (2007) Unconstrained tripolar hip implants: effect on hip stability. Clin Orthop Relat Res 455:202-208

24. Philippot R, Camilleri JP, Boyer B, Adam P, Farizon F (2009) The use of a dual articulation acetabular cup system to prevent dislocation after primary total hip arthroplasty: analysis of 384 cases at a mean follow-up of 15 years. Int Orthop 33:927-932

25. Bouchet R, Mercier N, Saragaglia D (2011) Posterior approach and dislocation rate: a 213 total hip replacements case-control study comparing the dual mobility cup with a conventional 28-mm metal head/polyethylene prosthesis. Orthop Traumatol Surg Res 97:2-7

26. Vielpeau C, Lebel B, Ardouin L, Burdin G, Lautridou C (2011) The dual mobility socket concept: experience with 668 cases. Int Orthop 35:225-230

27. Mohammed R, Hayward K, Mulay S, Bindi F, Wallace M (2015) Outcomes of dual-mobility acetabular cup for instability in primary and revision total hip arthroplasty. J Orthop Traumatol 16:9-13

28. Langlais FL, Ropars M, Gaucher F, Musset T, Chaix O (2008) Dual mobility cemented cups have low dislocation rates in THA revisions. Clin Orthop Relat Res 466:389-395 
29. Grazioli A, Ek ET, Rudiger HA (2012) Biomechanical concept and clinical outcome of dual mobility cups. Int Orthop 36:2411-2418

30. Hailer NP, Weiss RJ, Stark A, Karrholm J (2012) Dual-mobility cups for revision due to instability are associated with a low rate of re-revisions due to dislocation. Acta Orthop 83:566-571

31. Civinini R, Carulli C, Matassi F, Nistri L, Innocenti M (2012) A dual mobility cup is effective for reducing dislocations in isolated acetabular revisions. Clin Orthop Relat Res 470:3542-3548

32. Tarasevicius S, Robertsson $\mathrm{O}$, Dobozinskas $\mathrm{P}$, Wingstrand $\mathrm{H}$ (2013) A comparison of outcomes and dislocation rates using dual articulation cups and THA for intracapsular femoral neck fractures. Hip Int 23:22-26

33. Dripps RD, Lamont A, Eckenhoff JE (1961) The role of anesthesia in surgical mortality. JAMA 178:261-266

34. Harris WH (1969) Traumatic arthritis of the hip after dislocation and acetabular fractures: treatment by mold arthroplasty. An endresult study using a new method of result evaluation. J Bone Joint Surg Am 51:737-755

35. Loudon JR, Charnley J (1980) Subsidence of the femoral prosthesis in total hip replacement in relation to the design of the stem. J Bone Joint Surg Br 62:450-453

36. Engh CA, Massin P, Suthers KE (1990) Roentgenographic assessment of the biologic fixation of porous-surfaced femoral components. Clin Orthop Relat Res 257:107-128

37. DeLee JG, Charnley J (1976) Radiological demarcation of cemented sockets in total hip replacement. Clin Orthop Relat Res 121:20-32

38. Gruen TA, McNeice GM, Amstutz HC (1979) Modes of failure of cemented stem-type femoral components: a radiographic analysis of loosening. Clin Orthop Relat Res 141:17-27

39. Brooker AF, Bowerman JW, Robinson RA, Riley LH Jr (1973) Ectopic ossification following total hip replacement: incidence and a method of classification. J Bone Joint Surg Am 55:1629-1632

40. Liu X, Zhang X, Chen Y, Wang Q, Jiang Y, Zeng B (2011) Hidden blood loss in hip arthroplasty. J Arthroplast 26:1100-1105

41. Lachiewicz PF, Heckman DS, Soileau ES, Mangla J, Martell JM (2009) Femoral head size and wear of highly cross-linked polyethylene at 5 to 8 years. Clin Orthop Relat Res 467:3290-3296
42. Tarasevicius S, Kesteris U, Robertsson O, Wingstrand H (2006) Femoral head diameter affects the revision rate in total hip arthroplasty: an analysis of 1720 hip replacements with 9-21 years of follow-up. Acta Orthop 77:706-709

43. Chatrath V, Beaulé PE (2013) The changing paradigm of revision of total hip replacement in the presence of osteolysis. Instr Course Lect 62:215-227

44. Paprosky WG, Perona PG, Lawrence JM (1994) Acetabular defect classification and surgical reconstruction in revision arthroplasty. A 6-year follow-up evaluation. J Arthroplast 9:33-44

45. Cross MB (2015) Dual mobility acetabular components for revision THA. J Orthop Traumatol 16:21-22

46. Adam P, Philippe R, Ehlinger M, Roche O, Bonnomet F, Molé D, Fessy MH (2012) Dual mobility cups hip arthroplasty as a treatment for displaced fracture of the femoral neck in the elderly. A prospective, systematic, multicenter study with specific focus on postoperative dislocation. Orthop Traumatol Surg Res 98:296-300

47. Masonis JL, Bourne RB (2002) Surgical approach, abductor function, and total hip arthroplasty dislocation. Clin Orthop Relat Res 405:46-53

48. Demos HA, Rorabeck CH, Bourne RB, MacDonald SJ, McCalden RW (2001) Instability in primary total hip arthroplasty with the direct lateral approach. Clin Orthop Relat Res 393:168-180

49. Lecuire F, Bernareau I, Rubini J, Basso M (2004) Intra-prosthetic dislocation of Bousquet dual mobility socket. Rev Chir Orthop Reparatrice App Mot 90:249-255

50. Banzhof JA, Robbins CE, van der Ven A, Talmo CT, Bono JV (2012) Femoral head dislodgement complicating use of a dual mobility prosthesis for recurrent instability. J Arthroplast 28:543.e1-543.e3

51. Philippot R, Boyer B, Farizon F (2013) Intraprosthetic dislocation: a specific complication of the dual-mobility system. Clin Orthop Relat Res 471:965-970 